\title{
Maintenace Engineering in Process Plants
}

\author{
Karthik Silaipillayarputhur \\ Assistant Professor, Department of Mechanical Engineering, College of Engineering, King Faisal University, Saudi Arabia
}

\begin{abstract}
The continuous and uninterrupted operation of process plants which is most essential for their profitable performance depends on reliability and availability of all the critical process equipment. Maintenance department provides chief support for the safe, reliable and successful functioning of a process plant. Process critical equipment must be effectively monitored and maintained so that they can support the continuous production in the plant. Some of the key elements required for the successful functioning of the maintenance team are briefly outlined in this manuscript. Though it could be exhausting to conscientiously apply all such principles regularly, it shall be in the benefit of the organization to consider and apply such concepts as much as possible.
\end{abstract}

\section{Introduction}

Process industry make products from raw materials and they run continuously for several months before the plant is shut down for a scheduled overhaul. All process industries generally have high technology and they run as lean as possible. Process industry have several rotating equipment such as motors, pumps, fans/blowers, compressors, gearboxes and process equipment such as heat exchangers, cooling towers, steam traps, control valves, relief valves, pressure vessels, etc. Failure of such equipment could result in total stoppage of the plant resulting in down time, un-happy customers and several thousands of dollars of monetary loss.

Thus, it is very essential to have a strong maintenance team to ensure the safe and reliable operation of the plant at all times. The main objectives of a maintenance department would be to provide dependable and safe operation of equipment at all times, cost reduction, minimize downtime and to have extensive planning and execution of shut down jobs. The maintenance department must therefore come up maintenance practices and strategy to meet the objectives.

Diverse textbooks, papers, online resources concentrating on maintenance practices are available in the literature. Mobley [1] developed a maintenance engineering hand book wherein the proven best practices for maintenance, repair, overhaul, inventory management, root-cause analysis and performance management are discussed. Niebel [2] furnishes the material necessary to provide cost effective maintenance, details the use of barcoding in maintenance and discusses utilities management. Moubray [3] gives practical explanation on reliability centered maintenance and how it can be applied in an industry. Smith [4] examines the principles of root cause analysis and on how they could be applied to everyday situations within the process plant. Townsend [5] considers safe maintenance practices in a process plant. Silaipillayarputhur [6] discusses the available predictive maintenance techniques that could be applied to common chemical/process plant equipment. Therein the author discusses the various predictive maintenance techniques that are commonly applied to rotary and process critical equipment.

\section{Maintenance techniques}

Maintenance strategy have evolved over the last $60-70$ years. Consider Fig. 1 describing the maintenance techniques in the last several years. To begin with, the maintenance strategy was to service the equipment after break down. This means that the equipment ran continuously until it encountered failure. This is an unacceptable maintenance practice as when the equipment completely shuts down; it probably requires several expensive components to be replaced. Moreover, the break down could happen at an un-expected time causing the entire plant to shut down.

Thereafter, preventive maintenance techniques slowly came into practice, and they are relevant in certain situations even today. In preventive maintenance, the equipment is thoroughly re-conditioned in certain fixed intervals. This practice is very similar to changing engine oil in the car as per stipulations in the car manual. Though this practice ensures the reliability of the equipment, this practice leads to performing maintenance activities when they may not be really required. Therefore, preventive maintenance on all process critical equipment leads to wastage of valuable time and money.

Though several techniques such as reliability centered maintenance (RCM), total productive maintenance (TPM), total quality management (TQM), preventive 
maintenance (PM), predictive maintenance (PDM) are all available and widely discussed, it is almost impractical to apply one such technique for the maintenance of a process plant. The newer generation maintenance strategy would be to incorporate several aspects that would ensure safe and reliable operation of the plant with the least maintenance costs. In no particular order, some of the main elements may be summarized as follows:

(a) incorporation of computerized maintenance management system (MMS)

(b) effective spares planning and control

(c) inclusion of well-defined preventive maintenance jobs in the MMS

(d) integration of well developed predictive maintenance system linked with MMS

(e) review existing maintenance practices and establish new practices/techniques available in the market

(f) optimization of available resources

(g) vendor development and import substitution without compromising on quality

(h) employment of reliability studies and process safety management for the reliable and safe operation of equipment

(i) cross training and refresher training for technicians

All of the above listed items are discussed in the following section.

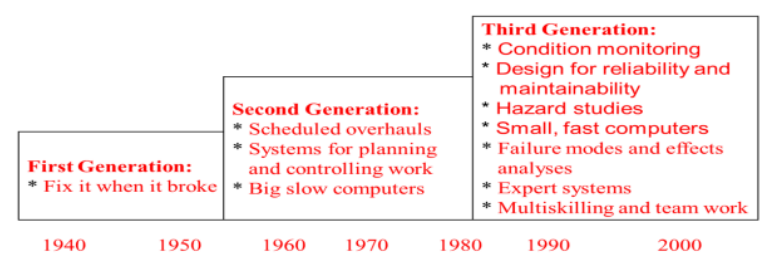

Figure 1. Changing maintenance techniques [6]

\section{Maintenance engineering}

As listed in the previous section, it is essential to cover various items to successfully manage a maintenance team. Only certain critical aspects are discussed in this paper and there could be several more depending on the nature of the business and the process itself. First and foremost it is very essential to have a computerized maintenance management system to handle regular maintenance and shut down activities effectively. MMS helps the engineers, supervisors, managers, technicians, operators, etc., to up-load the maintenance requests/activities in the MMS. MMS ensures that the maintenance activities are documented and not forgotten at a later time. Likewise, shut down activities must be listed in a well-defined sequence along with the required labor in the MMS. Since maintenance requests and activities are all listed in the software, the supervisor can schedule the activities based on priority, availability of resources, available working hours, and the equipment condition. A wellestablished MMS helps the organization in getting the work accomplished in a timely manner and in the most cost efficient way.

Spare parts planning and control helps the maintenance team to have the right spare and the required quantity on hand when it is needed. Having the correct spare part on hand helps the maintenance crew to execute the maintenance tasks without issues. The MMS can be linked with the spare part inventory so that the maintenance personnel can readily verify whether the required parts are available in the inventory to execute a given maintenance activity.

While setting up the spare parts inventory system, part details must be furnished precisely along with the preferred vendors. In addition, for every spare part, the minimum required inventory must be ascertained after careful evaluation. The order point for a given spare part must be chosen based on consumption history, lead-time, and the minimum required quantity at the plant.

A spare parts inventory system must be set up such that the parts are ordered automatically without going through the approval system. This helps in getting the parts ordered on time without any delays. It must be noted that spare parts held in the inventory costs several thousands of dollars and therefore the required quantity must be established after careful evaluation. Like food products, certain spare parts expire after a specific time. All these must be taken into account while setting up the spare parts inventory system. In the event of an unexpected total shutdown of the plant, several spare parts may be required for the shutdown activities. Therefore, it is sometimes beneficial to have an inventory system for the regular operations and a separate inventory system for shut down activities.

Spare parts must be received only after careful evaluation by the required personnel. Material test reports (MTR) and certificate of compliance (COC) must be checked before the parts are accepted in the inventory. An erroneous part can certainly create a tremendous issue, as the spare part shall not be useful when it is required the most.

Essential preventive maintenance activities in the plant should be identified after careful evaluation and must be added in the MMS system. The MMS system must alert the maintenance team when a certain item is due for routine inspection. This will help in addressing the preventive maintenance tasks in an organized manner. Regular cleaning of filters for HVAC units, cleaning of filtration units for cooling systems \& pumps, checking for leaks, oil level in gear boxes, pumps, compressors, checking for hot spots in an electrical drives, etc., can all be classified under preventive maintenance tasks. The frequency of preventive maintenance for a certain activity is chosen based on performance and past experiences. The preventive maintenance activities in the MMS system must be reviewed on a regular basis to keep the list as up to date as possible. It must be noted that preventive maintenance tasks reduces the possibility of having an unscheduled maintenance, minimizes catastrophic machinery failures, and above all minimizes the possibility of having an expensive downtime.

A well developed predictive maintenance system is also required for reliable and safe operation of equipment. Due to the costs involved in performing a thorough maintenance on the equipment, and due to time constraints it is only possible to perform a maintenance activity only when it is required. Several proven 
predictive maintenance techniques are available for rotary and process equipment. Any rotary equipment having a defect shall exhibit vibrations. Thus, vibration analysis is the most commonly employed technique to judge the operating condition and to detect defects in the rotary equipment. In parallel with the vibration analysis, lubrication analysis can be employed to analyze the operating condition of the equipment. Likewise, ultrasound, electrical imbalance analysis and infrared thermography can also be utilized to detect the defects in the equipment. These have been described in [7]. While in operation, all process critical equipment must be analyzed using the above techniques on a regular basis. When an equipment begins to exhibit an adverse change in the performance, then that equipment must be examined more regularly until it is gets closer to the alert level. Based on the machine's condition and down time availability the equipment can be taken down for service and a thorough maintenance must be performed on the equipment. Predictive maintenance must be linked with the MMS so that operating issues are captured and recorded for any further maintenance activities.

As a part of predictive maintenance, process critical equipment in the plant may be linked to the Digital Control System (DCS). This is certainly very useful as the control room operators, engineers, and mangers can continuously monitor the performance of the equipment. In addition, since the data is available in the system, the operating trend could be charted for further evaluation.

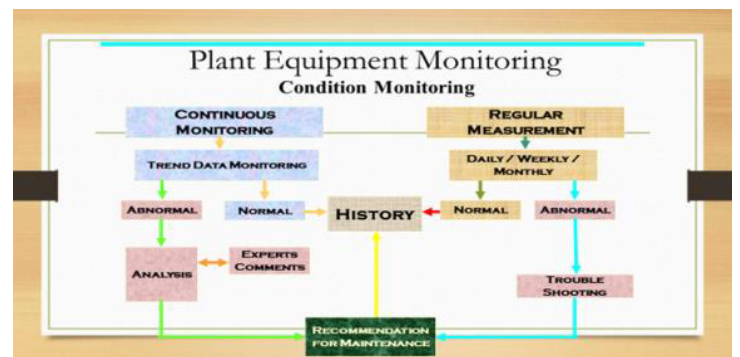

Figure 2. Condition monitoring using predictive maintenance practices

While performing a maintenance activity, it is very important to execute a thorough maintenance. The maintenance department must conduct the required inspections and activities on the equipment while it is taken down for service. Else, after the equipment start-up, it is very possible that a different issue could arise on the same equipment and pose an embarrassing situation for the maintenance team.

With the help of vendors, the maintenance engineers must review the existing maintenance practices and examine whether any new techniques are available in the market. The new technique may help the maintenance team to perform a certain maintenance activity quickly and more effectively. For example, until about a decade ago, lubrication for the fan/blower bearings was checked/dispensed using grease guns every fortnight. The new trend is to use an automatic lube dispenser wherein the technician does not have to lubricate the equipment for several months. Thus, it is certainly worthwhile to regularly check for new practices available and implement those wherever possible.
Keeping the future in mind, it is very beneficial to develop vendors in the near vicinity of the facility for maintenance tasks and for the procurement of parts consumed at the facility. Any process plant would require special cleaning facilities, furnace facilities, assembling facilities, rebuilding facilities, etc. In the long run, for faster service, it will be beneficial for the process industry to have such facilities neighboring the plant. Likewise, without compromising on quality, it may be worthwhile to check whether the long lead time items could be manufactured by local vendors. This will help in having quality parts on hard without being delayed for several months.

It is essential to integrate the principles of process safety management (PSM) and reliability engineering within the maintenance strategy. This helps in maintaining mechanical integrity of the equipment and assuring quality in maintenance activities. Reliability tools help to detect the factors contributing to the poor performance of the equipment, the interaction between the factors, expected time of failure and the effects of failure. Principles of process safety management help in identifying the root causes for an incident and issues before the startup of an equipment or a process. It also confirms contractor safety and ensures adequate training for the employees and contractors. These principles dictate that proper procedures are developed for maintenance $\&$ operations and that process hazards are identified by the application of reliability tools. PSM principles require that the procedures are regularly verified for accuracy and that adequate trainings and refresher trainings are provided to technicians. Inaddition, these principles direct the maintenance team to conduct audits regularly and plan for emergencies.

\section{Summary}

The author, using years of maintenance experience in process plants, has summarized some of the important aspects for the effective administration of a maintenance program. Each aspect described in this paper has enough value to be discussed as a separate paper and for brevity; the discussions have been kept as short as possible. It should be noted that for a successful management of a maintenance team in a process plant, it is almost unrealistic to adopt a single maintenance technique. Various other factors such as coordination between the maintenance and other departments, application of reliability principles during design phase and regular operations, conducting energy audits, establishing workshop with required facilities, etc., are all of importance. All these are beyond the scope of this paper.

Equations should be centred and should be numbered with the number on the right-hand side.

\section{References}

1. Mobley, K., Maintenance Engineering Handbook, 8th Ed., McGraw-Hill Education, (2014).

2. Niebel, B.W., Maintenance Management, 2nd Ed., CRC Press, (1994). 
3. Moubray, J., Raliability Centerd Maintenance, 2nd Ed., Industrial Press, ISBN-13: 978-0831131463, (1997).

4. Smith, W., Root Cause Analysis for Process Plants, LSA Publishing, (2012).
5. Townsend, A., Maintenance of Process Plant, 2nd Ed., Institution of Chemical Engineers, ISBN-13: 978-0852952924, 1992.

6. Silaipillayarputhur, K., Effective Maintenance Practices in a Process Plant, Journal of Applied Global Research, 6, no. 17, p. 90-103, 2013. 